\title{
PERSEPSI MASYARAKAT DAN PERUSAHAAN TERHADAP PROGRAM CORPORATE SOCIAL RESPONSIBILITY (CSR) PT BUKIT ASAM UNIT PELABUHAN TARAHAN, KOTA BANDAR LAMPUNG
}

\author{
(The Perception of Society and Company on Corporate Social Responsibility (CSR) Program at \\ PT Bukit Asam Unit Pelabuhan Tarahan, Bandar Lampung)
}

Fadlan Satria, Dewangga Nikmatullah, Indah Nurmayasari

Jurusan Agribisnis, Fakultas Pertanian, Universitas Lampung, Jl. Prof. Dr. Soemantri Brojonegoro No.1 Bandar Lampung 35141, Telp 081377587711, e-mail: fadscrab@ gmail.com

\begin{abstract}
CSR (Corporate Social Responsibility) is a vital element for company in order to manage good relationship with local people and surroundings. CSR were made to maintain the balance between corporate interests and the welfare of surrounding community. Hence, this study aims to find out the level of CSR Program implementation at PT Bukit Asam Unit Pelabuhan Tarahan, the perception of society and company, and the relationship between the perception and the level of the CSR Program implementation. The location of this study has been chosen puposively in Tarahan Village, Panjang Subdistrict, Bandar Lampung. Respondents of this research were 61 of local people and 6 of company staffs. Data were collected in April - May 2017. This research used a survey method with descriptive analysis and used nonparametric statistics test correlation Rank Spearman to test the hypothesis. The results showed that the level of program implementation is in a high classification, the perception of society on CSR Program is in good classification, the perception of company to CSR Program is also in good classification. There is no significant correlation between the perception of society and program implementation, in other hand there is significant correlation between the perception of company and program implementation of PT Bukit Asam Unit Pelabuhan Tarahan.
\end{abstract}

Key words: CSR Program, the perception of society, the perception of company

\section{PENDAHULUAN}

Aktivitas perusahaan memiliki berbagai dampak terhadap lingkungan, baik lingkungan internal maupun lingkungan eksternal. Dampak terhadap lingkungan eksternal sering kali menjadi sorotan, karena pengaruhnya terhadap orang lain atau lingkungan sosial di luar perusahaan. Hal tersebut menimbulkan pendapat bahwa pelaku bisnis atau perusahaan memiliki tanggungjawab sosial untuk mengupayakan suatu kebijakan serta membuat keputusan atau melaksanakan tindakan yang sesuai dengan tujuan dan nilai-nilai masyarakat (Solihin 2009).

Perusahaan sebagai salah satu pelaku dalam pembangunan ekonomi nasional, sudah selayaknya tidak hanya bertujuan memperoleh keuntungan finansial namun juga perlu berkontribusi bagi masyarakat dan lingkungan di sekitarnya. Sebagaimana yang disebutkan oleh Wibisono (2007) bahwa tanggung jawab perusahaan kepada pemangku kepentingan untuk berlaku etis, meminimalkan dampak negatif dan memaksimalkan dampak positif yang mencakup aspek ekonomi, sosial, dan lingkungan (triple bottom line) dalam rangka mencapai tujuan pembangunan berkelanjutan. Oleh karenanya dalam dunia usaha kini hadir konsep CSR sebagai bentuk nyata kepedulian perusahaan akan tanggung jawab sosial dan lingkungan. Salah satu perusahaan yang menerapkan CSR adalah PT Bukit Asam Unit Pelabuhan Tarahan, Bandar Lampung.

Persepsi masyarakat dan perusahaan yang diwakili karyawan dapat menjadi penilaian atas keberhasilan suatu kegiatan dari Program CSR perusahaan, penilaian tersebut dapat digunakan sebagai pertimbangan kebijakan perusahaan untuk program CSR yang akan dilakukan pada tahun berikutnya. Program CSR yang dibentuk perusahaan haruslah yang berdasarkan pada kebutuhan dan perbaikan kesejahteraan masyarakat sekitar perusahaan. Berdasarkan uraian tersebut, ingin diketahui bagaimana persepsi masyarakat sekitar perusahaan yang menerima program CSR dan persepsi perusahaan terhadap program yang telah dijalankan, maka tujuan penelitian ini adalah mengetahui tingkat penerapan program CSR, 
mengetahui persepsi masyarakat dan perusahaan dengan program, dan mengetahui hubungan antara persepsi masyarakat dan persepsi perusahaan dengan penerapan program CSR PT Bukit Asam (PTBA).

\section{METODE PENELITIAN}

Metode penelitian yang digunakan adalah metode survai. Penelitian ini dilakukan di Desa Tarahan Kecamatan Panjang Kota Bandar Lampung.Lokasi penelitian dipilih secara sengaja (purposive) dengan pertimbangan desa tersebut berbatasan langsung dengan PT Bukit Asam Unit Pelabuhan Tarahan dan merasakan langsung pelaksanaan program CSR. Pengambilan data dilakukan pada bulan April-Mei 2017.

Populasi pada penelitian ini adalah masyarakat Desa Tarahan di RT 20 dan 21 yakni sebanyak 310. Sampel diambil secara proportional random sampling atau penentuan sampel secara acak yakni sebanyak 61 responden. Responden perusahaan yang diwakili oleh 6 karyawan dipilih secara sengaja (purposive) karena secara langsung terkait dengan Program CSR PTBA.

Data yang digunakan dalam penelitian ini adalah data primer dan data sekunder. Data primerdiperoleh secara langsung melalui proses wawancara serta pengamatan langsung pada masyarakat sekitar dan karyawan PTBA dengan dipandu daftar kuesioner. Data sekunder diperoleh dari badan dan instansi terkait di daerah penelitian.

Metode analisis data yang digunakan pada penelitian ini adalah deskriptif kualitatif, sedangkan pengujian hipotesis menggunakan statistik nonparametrik korelasi Rank Spearman (Siegel2011). Variabel-variabel pada penelitian ini yaitu persepsi masyarakat $\left(\mathrm{X}_{1}\right)$ dan persepsi perusahaan $\left(\mathrm{X}_{2}\right)$. Indikator variabel $\mathrm{X}$ yaitu bentuk kegiatan, frekuensi kegiatan, sasaran kegiatan, dan fasilitas kegiatan CSR yang diukur dengan menggunakan teknik skoring 1-3.

Karena jumlah sampel yang digunakan adalah lebih besar dari 10 (sepuluh) responden, maka pengujian terhadap H1 dilanjutkan dengan uji-t.

Kriteria pengambilan keputusan:

1. Jika $\mathrm{t}_{\text {-hitung }} \leq \mathrm{t}_{\text {-tabel }}(\mathrm{n}-2)$ maka tolak $\mathrm{H} 1$ pada $\alpha$ 0.05 atau $\alpha 0.01$, artinyatidak ada hubungan nyata pada kedua variabel.
2. Jika $\mathrm{t}_{\text {-hitung }}>\mathrm{t}_{\text {-tabel }}(\mathrm{n}-2)$, maka terima $\mathrm{H} 1$ pada $\alpha$ 0.05 atau $\alpha 0.01$, artinya terdapat hubungan yang nyata pada kedua variabel.

\section{HASIL DAN PEMBAHASAN}

\section{Kondisi Daerah Penelitian}

PT Bukit Asam (PTBA) merupakan salah satu perusahaan Badan Usaha Milik Negara (BUMN). PTBA Unit Pelabuhan Tarahan merupakan pelabuhan/dermaga terbesar yang dimiliki PT Bukit Asam dengan luas areal $55 \mathrm{Ha}$. PTBA Unit Pelabuhan Tarahan terletak $18 \mathrm{~km}$ dari Kota Bandar Lampung dan $6 \mathrm{~km}$ di sebelah selatan Pelabuhan Panjang. PTBA merupakam salah satu BUMN yang melaksanakan Program CSR dengan baik. Bentuk pelaksanaan Program CSR PTBA yaitu dalam bidang pendidikan atau pelatihan memberikan beasiswa "Ayo Sekolah" kepada 2.819 siswa tingkat SD sampai SLTA; penyaluran beasiswa kepada 68 orang mahasiswa yang mengikuti pendidikan di Institut Pertanian Bogor, Universitas Sriwijaya dan Politeknik Sriwijaya.

Pengembangan sarana umum dilakukan perbaikan jalan, pembangunan jembatan, dan pembangunan pagar pengamanan. Bidang peningkatan sarana ibadah bentuk kegiatan yang dilakukan adalah perbaikan tempat ibadah, bantuan dana masjid, dan pemberian bantuan fasilitas sarana ibadah. Pelestarian alam bentuk kegiatannya berupa pemberian bantuan bibit tanaman pohon penghijauan dan tanaman produktif, kegiatan gotong-royong kebersihan lingkungan dan penanaman pohon, pemberian benih ikan dan pembangunan tanggul-tanggul. Bidang sosial kemasyarakatan dilakukan pembinaan anggota Pos Pemberdayaan Keluarga (Posdaya) dan bantuan untuk usaha-usaha kelompok yang dimiliki masyarakat.

Desa Tarahan merupakan salah satu desa yang ada di Kabupaten Lampung Selatan. Desa Tarahan memiliki jumlah penduduk 7.640 jiwa dengan jumlah kepala keluarga 1.546 pada tahun 2016. Penduduk Desa Tarahan terdiri atas laki-laki sebanyak 3.800 jiwa dan perempuan sebanyak 3.840 jiwa. 
Tabel 1. Persepsi masyarakat Desa Tarahan terhadap Program CSR PTBA

\begin{tabular}{llcc}
\hline & Indikator & $\begin{array}{c}\text { Rata-rata } \\
\text { (skor) }\end{array}$ & Klasifikasi \\
\hline 1. & $\begin{array}{l}\text { Persepsi terhadap } \\
\text { bentuk kegiatan }\end{array}$ & 32,05 & Baik \\
2. & $\begin{array}{l}\text { Persepsi mengenai } \\
\text { frekuensi kegiatan }\end{array}$ & 8,66 & Baik \\
3. & $\begin{array}{l}\text { Persepsi mengenai } \\
\text { sasaran }\end{array}$ & 9,99 & Baik \\
$4 . \quad \begin{array}{l}\text { Persepsi mengenai } \\
\text { fasilitas }\end{array}$ & 11,71 & Baik \\
\hline & $\begin{array}{l}\text { Persepsi masyarakat } \\
\text { terhadap Program } \\
\left.\text { CSR PTBA (X } X_{1}\right)\end{array}$ & 62,13 & Baik \\
\hline
\end{tabular}

\section{Persepsi Masyarakat}

Menurut Sugihartono (2007) persepsi adalah kemampuan otak dalam menerjemahkan stimulus atau proses untuk menerjemahkan stimulus yang masuk ke dalam alat indera manusia. Persepsi merupakan salah satu aspek psikologis yang penting bagi manusia dalam merespon kehadiran berbagai aspek dan gejala di sekitarnya. Pada penelitian ini persepsi masyarakat terhadap Program CSR PTBA dapat dilihat dari indikator yaitu persepsi terhadap bentuk kegiatan CSR, persepsi mengenai frekuensi pelaksanaan CSR, persepsi mengenai sasaran Program CSR, dan persepsi mengenai fasilitas Program CSR(Tabel 1).

Berdasarkan Tabel 1 di atas, persepsi masyarakat terhadap Program CSR PTBA berada pada klasifikasi baik. Mayoritas masyarakat sekitar perusahaan menganggap bahwa bentukkegiatankegiatan Program CSR tersebut sudah baik dan tepat sasaran, serta fasilitas dan frekuensi pelaksanaannya sudah baik. Masyarakat menganggap Program CSR yang telah dilakukan bermanfaat untuk masyarakat sekitar perusahaan. Program CSR yang diberikan memiliki manfaat yaitu mendapatkan keahlian dan keterampilan profesional, masyarakat juga mendapatkan keterampilan manajemen yang baik dan kreatif dalam memecahkan masalah, dan memperoleh pengalaman.

Program CSR PTBA dikatakan baik apabila empat indikator tersebut telah dilakukan dengan baik dan mendapat respon yang baik pula dari masyarakat. Program CSR PTBA dibentuk berdasarkan kebutuhan masyarakat lingkungan perusahaan.
Tabel 2. Persepsi perusahaan terhadap Program CSR PTBA

\begin{tabular}{llcc}
\hline No. & Indikator & Rata-rata & Klasifikasi \\
\hline 1. & $\begin{array}{l}\text { Persepsi terhadap } \\
\text { bentuk kegiatan }\end{array}$ & 22,77 & Baik \\
2. & $\begin{array}{l}\text { Persepsi mengenai } \\
\text { frekuensi kegiatan }\end{array}$ & 5,29 & Baik \\
3. & $\begin{array}{l}\text { Persepsi mengenai } \\
\text { sasaran }\end{array}$ & 6,97 & Baik \\
$4 . \quad \begin{array}{l}\text { Persepsi mengenai } \\
\text { fasilitas }\end{array}$ & 8,88 & Baik \\
\hline & $\begin{array}{l}\text { Persepsi perusahaan } \\
\text { terhadap Program CSR } \\
\text { PTBA }\left(\mathrm{X}_{2}\right)\end{array}$ & 45,97 & Baik \\
\hline
\end{tabular}

\section{Persepsi Perusahaan}

Persepsi perusahaan merupakan hal yang penting bagi perusahaan untuk mempersiapkan programprogram CSR yang lebih baik dan tepat sasaran. Persepsi karyawan dapat mewakili perusahaan, karena terdapat kombinasi antara pengalaman karyawan dengan keadaan di lapangan dan respon dari masyarakat.Tujuan CSR perusahaan harus sesuai kebutuhan masyarakat dan seimbang dengan visi misi perusahaan (Prutina 2016).

Program CSR yang diberikan perusahaan kepada masyarakat sekitar memiliki manfaat yaitu mendapatkan keahlian dan keterampilan profesional yang belum tentu masyarakat dapat terima atau masyarakat tidak memiliki dana untuk mengadakannya, mendapatkan keterampilan manajemen yang membawa pendekatan yang baik dan kreatif dalam memecahkan masalah, dan memperoleh pengalaman dari pelatihan yang perusahaan berikan sehingga masyarakat dapat menjalankan bisnis.

Berdasarkan Tabel 2, persepsi perusahaan PTBA terhadap Program CSR PTBA berada pada klasifikasi baik yang dilihat dari persepsi terhadap bentuk kegiatan, frekuensi kegiatan, sasaran program, dan fasilitas program.

Perusahaan menganggap bahwa pelaksanaan kegiatan-kegiatan CSR tersebut sudah baik dan tepat sasaran, serta fasilitas dan frekuensi pelaksanaannya sudah sangat baik. Perusahaan telah merancang berbagai kegiatan melalui Program CSR perusahaan agar bermanfaat untuk masyarakat sekitar perusahaan. 
Tabel 3. Skor interval persepsi masyarakat dan perusahaan terhadap Program CSR

\begin{tabular}{|c|c|c|c|}
\hline Variabel & Skor Interval & $\begin{array}{c}\text { Rata- } \\
\text { rata }\end{array}$ & Klasifikasi \\
\hline $\begin{aligned} \mathrm{X}_{1}: & \text { Persepsi } \\
& \text { masyarakat } \\
& \text { terhadap } \\
& \text { Program } \\
& \text { CSR }\end{aligned}$ & $\begin{array}{l}39,16-50,38 \\
\text { (Kurang baik) } \\
50,39-61,61 \\
\text { (Cukup baik) } \\
61,62-72,83 \\
\text { (Baik) }\end{array}$ & 62,13 & Baik \\
\hline $\begin{aligned} \mathrm{X}_{2}: & \text { Persepsi } \\
& \text { perusahaan } \\
& \text { terhadap } \\
& \text { Program } \\
& C S R\end{aligned}$ & $\begin{array}{l}34,49-40,21 \\
\text { (Kurang baik) } \\
40,22-45,94 \\
\text { (Cukup baik) } \\
45,95-51,65 \\
\text { (Baik) }\end{array}$ & 45,97 & Baik \\
\hline
\end{tabular}

Persepsi masyarakat terhadap Program CSR berada pada klasifikasi baik karena rata-rata skor yang didapat adalah 62,13 dengan skor interval terendah 39,16 dan skor interval tertinggi 72,83, sedangkan persepsi perusahaan terhadap Program CSR berada pada klasifikasi baik dengan rata-rata skor 45,97 karena skor interval terendah berada pada 34,49 dan skor interval tertinggi 51,65. Skor interval persepsi masyarakat dan perusahaan terhadap Program CSRyang dapat dilihat pada Tabel 3.

\section{Tingkat Penerapan CSR PTBA}

Tingkat Penerapan CSR PTBA (Tabel 4) dinilai telah memenuhi kebutuhan masyarakat yang tinggal di sekitar perusahaan. Frekuensi kegiatan Program CSR telah dilakukan cukup sering di dalam masyarakat. Penelitian ini sejalan dengan penelitian yang dilakukan Chew (2015) bahwa suatu program CSR yang dilakukan perusahaan dapat berhasil apabila berkaitan dengan kepentingan umum dan memiliki komitmen yang kuat untuk membangun kesejahteraan masyarakat sekitar.

Berdasarkan Tabel 4, tingkat penerapan Program CSR PT Bukit Asam Unit Pelabuhan Tarahan dapat dilihat dari bentuk kegiatan CSR (Pendidikan dan pelatihan, peningkatan kesehatan masyarakat, pengembangan sarana umum, peningkatan sarana ibadah, pelestarian alam, dan bentuk sosial kemasyarakatan), frekuensi pelaksanaan CSR, sasaran CSR, dan fasilitas pendukung CSR.
Tabel 4. Tingkat penerapan Program CSR PTBA

\begin{tabular}{clll}
\hline No. & Indikator & Rata-rata & Klasifikasi \\
\hline 1. & Bentuk kegiatan & 12,93 & Baik \\
& CSR & & \\
2. & $\begin{array}{l}\text { Frekuensi } \\
\text { kegiatan CSR }\end{array}$ & 12,49 & Sering \\
3. & $\begin{array}{l}\text { Sasaran } \\
\text { Program CSR }\end{array}$ & 11,21 & Cukup tepat \\
4. & $\begin{array}{l}\text { Fasilitas } \\
\text { Program CSR }\end{array}$ & 12,07 & Mendukung \\
\hline & $\begin{array}{l}\text { Tingkat } \\
\text { penerapan }\end{array}$ & 48,70 & Baik \\
& Program CSR & & \\
\hline
\end{tabular}

Bentuk kegiatan-kegiatan yang dilakukan dalam penerapan Program CSR PTBA terbagi dalam berbagai bidang yaitu, pendidikan dan pelatihan, peningkatan kesehatan masyarakat, pengembangan sarana umum, peningkatan sarana ibadah, pelestarian alam dan bantuan sosial kemasyarakatan. Masyarakat menganggap bahwa sasaran pelaksanaan Program CSR PTBA sudah cukup tepat. Masyarakat menilai bahwa penerima ataupun masyarakat yang merasakan dampak dari program CSR PTBA sudah baik dan cukup tepat sasaran. Masyarakat menganggap bahwa fasilitas dari program CSR PTBA sudah mendukung dari berbagai bidang. Fasilitas yang diberikan dianggap dapat membantu memenuhi kebutuan dan menunjang kehidupan masyarakat sekitar.

\section{Pengujian Hipotesis}

Hubungan antara persepsi masyarakat dan persepsi perusahaan dengan tingkat penerapan Program CSR PTBA dianalisis dengan statistika non parametrik uji korelasi Rank Spearman. Hasil pengujian statistik terhadap variabel-variabel tersebut dapat dilihat pada Tabel 5.

Tabel 5. Hasil analisis hubungan antara variabel persepsi masyarakat dan perusahaan dengan variabel Program CSR

\begin{tabular}{|c|c|c|c|c|c|}
\hline No & $\begin{array}{c}\text { Variabel } \\
\mathrm{X}\end{array}$ & $\begin{array}{c}\text { Variabel } \\
\mathrm{Y}\end{array}$ & $\begin{array}{c}\text { Koefisien } \\
\text { korelasi }\left(\mathrm{r}_{\mathrm{s}}\right)\end{array}$ & $\begin{array}{c}\text { sig. } \\
\text { (2-tailed) }\end{array}$ & $\begin{array}{c}\mathrm{t}- \\
\text { hitung }\end{array}$ \\
\hline 1 & $\begin{array}{l}\text { Persepsi } \\
\text { masyarakat } \\
\text { terhadap } \\
\text { program }\end{array}$ & $\begin{array}{l}\text { Program } \\
\text { CSR }\end{array}$ & 0,099 & 0,447 & $0,764^{\mathrm{tn}}$ \\
\hline 2 & $\begin{array}{l}\text { Persepsi } \\
\text { perusahaan } \\
\text { terhadap } \\
\text { program }\end{array}$ & & 0,820 & 0,046 & $2,863 *$ \\
\hline \multicolumn{6}{|c|}{ Keterangan: } \\
\hline & $\begin{array}{l}\text { : Rank Spea } \\
: \text { Nyata pada } \\
: \text { Tidak nyat }\end{array}$ & $\begin{array}{l}\text { man } \\
\text { taraf keperc } \\
\text { pada taraf }\end{array}$ & $\begin{array}{l}\text { aan } 95 \%(\alpha= \\
\text { ercayaan } 95 \%\end{array}$ & $\begin{array}{l}5, \mathrm{t} \text {-tabel } \\
\text { an } 99 \%\end{array}$ & 663) \\
\hline
\end{tabular}


Berdasarkan Tabel 5, dapat diketahui nilai t-hitung 0,764 lebih kecil dari t-tabel 1,663, maka tolak $\mathrm{H}_{1}$ yang artinya tidak terdapat hubungan antara persepsi masyarakat dengan penerapan Program CSR PTBA. Nilai t-hitung 2,863 lebih besar dari t-tabel 1,663, maka terima $\mathrm{H}_{1}$ yang artinya terdapat hubungan antara persepsi perusahaan dengan penerapan Program CSR PTBA.

\section{Hubungan Antara Persepsi Masyarakat DenganTingkat Penerapan Program CSR PTBA}

Berdasarkan hasil pengujian didapatkan nilai thitung sebesar 0,764. Nilai t-hitung tersebut lebih kecil dari t-tabel 1,663 sehinga menunjukkan bahwa persepsi masyarakat tidak berhubungan nyata dengan tingkat penerapan program CSR PTBA. Hal ini dapat dilihat pada indikator persepsi masyarakat yaitu persepsi mengenai bentuk kegiatan, frekuensi kegiatan, sasaran program, dan fasilitas program. CSR PTBA menyerahkan kewenangan pembagian bantuan program kepada pejabat desa setempat atau RT, sehingga kebanyakan masyarakat mengetahui bahwa bantuan tersebut berasal dari pemerintah, namun ada juga yang telah mengetahui bantuan tersebut berasaldari PTBA.

Hal tersebut juga disebabkan kurangnya informasi dan sosialisasi dengan kegiatan CSR yang diterima masyarakat. Masyarakat belum aktif mencari informasi tentang bantuan dan hanya menerima intruksi dari pejabat setempat, sehingga bantuan dianggap berasal dari pemerintah walaupun tidak semua masyarakat yang belum paham. Hubungan yang baik harus dibangun antara perusahaan dengan masyarakat dengan adanya CSR. Masyarakat diharapkan terbantu dalam meningkatkan pendidikan, kualitas lingkungan, dan kesehatan yang diwujudkan melalui programprogram yang telah disiapkan sebelumnya (Hailu 2013). Sejalan dengan penelitian Kusnaini (2013) menyatakan bahwa perusahaan sebaiknya melakukan sosialisasi mengenai program CSR kepada masyarakat, hal ini diperlukan agar permasalahan sosial dan lingkungan dalam masyarakat dapat terselesaikan dengan baik.

Menurut hasil penelitian yang dilakukan oleh Erni tahun 2006 mengenai persepsi masyarakat terhadap sistem agroforestri berbasis karet klon, faktor lain yang juga menjadi pertimbangan petani atau yang menjadi bahan pembentuk persepsi petani adalah faktor-faktor psikologis serta sosial yang turut mempengaruhi cara berfikir petani seperti keberhasilan program yang telah dijalankan oleh masyarakat di tempat lain, usaha bersama yang dilakukan masyarakat dengan pembuat program, dan kemudahan-kemudahan akses yang diterima masyarakat dalam menjalankan program tersebut. Lebih jauh hasil penelitian Musoleha (2014) menyatakan bahwa program yang dijalankan harus menyentuh kebutuhan sosial, ekonomi, dan lingkugan serta memberikan manfaat yang besar bagimasyarakat dan lingkungan sekitar. Kesimpulan yang dapat diambil dari hasil penelitian yang dilakukan oleh Erni (2006) tersebut dan memiliki relevansi terhadap penelitian ini adalah bahwa persepsi masyarakat dapat terbentuk baik apabila masyarakat memandang keberhasilan program yang telah dilakukan sebelumnya dan fasilitasfasilitas yang akan diterima oleh masyarakat dapat mempermudah dan membantu kehidupan masyarakat.

\section{Hubungan Antara Persepsi Perusahaan Dengan Tingkat Penerapan Program CSR PTBA}

Berdasarkan hasil pengujian didapatkan nilai thitung sebesar 2,863. Nilai t-hitung lebih besar daripada t-tabel yaitu 1,663. Hal tersebut menunjukkan bahwa persepsi perusahaan berhubungan nyata terhadap tingkat penerapan program CSR PTBA.

Menurut Ismail (2009), CSR merupakan komitmen perusahaan untuk melakukan perbaikan lingkungan maupun ekonomi masyarakat umum sekitar perusahaan, sehingga dibutuhkan konsep yang jelas agar tercapainya tujuan CSR perusahaan. Perusahaan menganggap bahwa telah melakukan CSR dengan baik, melihat potensi daerah sekitar, serta telah melakukan kegiatan-kegiatan yang dapat mengembangkan komunitas dan masyarakat sekitar perusahaan. PTBA telah memperhatikan kepentingan masyarakat dalam pelaksanaan kegiatan-kegiatan program CSR. Perusahaan menganggap dengan adanya CSR untuk masyarakat maka akan membuat hubungan yang bersifat mutualistik dan baik antara perusahaan dengan masyarakat serta bentuk kontribusi perusahaan dalam pemberdayaan masyarakat.

Bentuk kegiatan yang dilakukan perusahaan dalam program CSR dianggap telah berdasarkan pemberdayaan masyarakat sekitar. Permberdayaan dilakukan dalam upaya untuk (terus menerus) meningkatkan harkat dan martabat lapisan masyarakat "bawah" yang tidak mampu 
melepaskan diri dari perangkap kemiskinan dan keterbelakangan. Dengan kata lain, pemberdayaan masyarakat adalah meningkatkan kemampuan dan meningkatkan kemandirian masyarakat. Perusahaan menilai telah semaksimal mungkin bekerjasama dengan masyarakat dalam menyukseskan program agar tercapainya tujuan program CSR dengan baik. Tanggung jawab perusahaan selain usaha-usaha yang dijalankan adalah menyeimbangkan dengan kepentingan sosial dan lingkungan (Palaniammal 2016).

\section{KESIMPULAN}

Berdasarkan hasil penelitian disimpulkan bahwa tingkat penerapan program CSR PTBA berada pada klasifikasi baik. Artinya kegiatan-kegiatan dalam rangkaian program CSR telah dilaksanakan dengan baik oleh perusahaan maupun masyarakat. Persepsi masyarakat dan perusahaan terhadap program CSR PTBA berada pada klasifikasi baik. Artinya masyarakat dan perusahaan menganggap bahwa program CSR yang dibentuk perusahaan telah berjalan dengan baik dan bermanfaat bagi kedua pihak. Tingkat persepsi masyarakat tidak berhubungan nyata terhadap tingkat penerapan program, sedangkan persepsi perusahaan berhubungan nyata terhadap tingkat penerapan program.

\section{DAFTAR PUSTAKA}

Chew TL. 2015. The impact of employee perception of CSR practices on organizational commitment and role behaviors, IJRAOB, 1 (4): 1-15. http://globalbizresearch.org/files 15044_ijraob_teo-lamchew_ellishanasruddin342126.pdf. [5 Januari 2018].

Erni B. 2006. Persepsi petani terhadap risiko dalam mengadopsi sistem agroforestri berbasis karet klon. JIIA, 1 (4): 9-12. http://jurnal.fp.unila.ac.id/index.php/JIA/issue /view/52. [10 November 2017].
Hailu FK. 2013. Perception of local community on corporate social responsibility of brewery firms in Ethiopia. IJSR, 6 (14): 12-16. http://www.allresearchjournal.com/archives/2 016/vol2issue4/PartA/2-3-102.pdf. [5 Januari 2018].

Ismail M. 2009. Corporate social responsibility and its role in community development. IJSR, 2 (11): 10-11. www.sosyalarastirmalar.com/ cilt2/sayi9pdf/ismail_maimunah.pdf. Januari 2018].

Kusnani DK. 2013. Persepsi masyarakat terhadap program corporate social responsibility (CSR) PT PLN sektor pembangkitan Tarahan Provinsi Lampung. JIIA, 1 (2): 140-148. http://jurnal.fp.unila.ac.id/index.php/JIA/issue /view/31. [10 November 2017].

Musoleha T. 2014. Persepsi masyarakat terhadap program kemitraan dan bina lingkungan (PKBL) PTPN VII unit usaha Rejosari Kecamatan Natar Kabupaten Lampung Selatan. JIIA, 2 (4): 390-398. http:// jurnal.fp.unila.ac.id/index.php/JIA/issue/view/ 99. [10 November 2017].

Palaniammal VS. 2016. Employees perception about corporate social responsibility in Nag Yang Shoes. IJRASET, 4 (9), 2-11. www.ijraset.com. [5 Januari 2018].

Prutina. 2016. Employees perception of corporate social responsibility. JEL, 1 (25): 239-260. http://ssst.edu.ba/upload/galleries/CV/CBDA NAPRUTINA_CV_june2016(1).pdf. [5 Januari 2018].

Siegel S. 2011. Statistik Non-Parametrik IlmuIlmu Sosial. PT Gramedia Pustaka Utama. Jakarta.

Solihin. 2009. Masyarakat, Bisnis dan Perusahaan (Corporate Social Responsibility). PT Indeks. Jakarta.

Sugihartono. 2007. Psikologi Pendidikan. UNY Press. Yogyakarta

Wibisono Y. 2007. Membedah Konsep dan Aplikasi CSR (Corporate Social Responsibility). Fascho Publishing. Gresik. 